\author{
Karina SACHPAZIDU-WÓJCICKA, PhD \\ Faculty of Economics and Management, University of Bialystok \\ e-mail: sachpazidu@uwb.edu.pl \\ ORCID: 0000-0003-2654-499X
}

DOI: $10.15290 /$ oes.2018.04.94.22

\title{
THE IMPORTANCE OF COOPERATION IN INNOVATIVENESS AND COMPETITIVENESS OF COMPANIES
}

\begin{abstract}
Summary
Innovation is one of the key sources of achieving competitive advantage by enterprises, whereas the cooperation within the framework of the innovation process is becoming increasingly important as it generates the company's innovativeness and higher competitive advantage. The main objective of the paper is to determine the forms and the level of cooperation in Polish companies while taking into consideration its sources and nature and to determine the importance of cooperation in gaining the competitiveness and innovativeness of Polish enterprises. The study, which was conducted on the sample of 100 companies, specified the conditions for cooperation of Polish companies. The frequency of the cooperation undertaken for innovation was not impressive - usually the company cooperated with only one entity. The nature of cooperation for the most part had a national dimension. The analysis of research results showed that Polish companies are not sufficiently involved in the cooperation with companies and especially with research units.
\end{abstract}

Key words: innovativeness, cooperation for innovation, external sources of innovation, technology

JEL classification: L01, M02, O30

\section{Introduction}

In contemporary economy the cooperation within the innovative process is becoming more and more important. Thanks to cooperation enterprises stand the chance to introduce innovative solutions, while reducing the costs and the risk because of sharing them with the cooperating entities. It is essential in case of small, medium-sized and large companies. Irrespective of its size, an enterprise achieves benefits that would be impossible to achieve individually. Thus, the cooperation for innovation is becoming an important factor in the innovative process as it enables enterprises to achieve competitive advantage and increase the general innovation level. The premise of initiating research is the issue of low innovation level and weak competitive position of Polish enterprises as well as the insufficient degree to which Polish enterprises make use of the cooperation for innovation. The paper presents the cooperation for innovation that is observed presently in Polish enterprises. The 
main aim of the paper is to specify the forms and the level of cooperation that are noticeable in Polish companies, while taking into consideration its sources and character and also to define the importance of the cooperation for innovation on the real innovation level of Polish companies. Particular issues regarding the cooperation for innovation were specified on the basis of the research conducted on the sample of 100 Polish industrial enterprises. The data was collected during individual surveys conducted with the highest management representatives or with the owners of the analyzed enterprises. The research specified the level of cooperation taking place in Polish companies including its specific forms. Additionally, the importance for innovation and competitiveness was analyzed here. The Author formulated the recommendations for enterprises in terms of the increase of their innovation level by means of the cooperation for innovation.

\section{Cooperation for innovation and innovation level of enterprises - theoretical aspects}

Enterprises seek competitive advantages in various activity spheres, in marketing, production, research and development or company management. It becomes essential to efficiently manage the processes of implementing new solutions in terms of either the product or the process. Innovation is one of the key sources of achieving competitive advantage. In order to compete enterprises need to implement new technologies, products, services or organization systems that constitute the condition of the higher innovation level. Innovation level may be achieved using various methods and while using many sources and combining them [Fagerberg et al., 2004, pp. 114-115].

Presently the dominating paradigm in the evaluation of the innovation level is the knowledge-based approach that is based on the necessity to increase financial outlays on the research and development (R\&D) activity and on the substantial institutional support of innovation processes. The creation of own research and development units and the elaboration of technologies within one's own resources are too costly and risky for the majority of Polish enterprises. It is confirmed by the general low innovation level of Polish enterprises as well as by their low positions in the rankings of the innovation level [Innovation Union Scoreboard 2014, 2015, 2017]. The ways of obtaining technologies and using the knowledge taken from the inner structure of the enterprise (that actively initiates effective innovation activity) that were suggested by Poland's innovation policy within the expanded domestic R\&D activity are most frequently out of reach of Polish companies. Hence the cooperation for innovation (that is based chiefly on mutually elaborated, verified and ready solutions) is becoming the main chance for increasing the competiveness and innovation level of Polish companies. The obtainment of technologies within the cooperation is also cheaper than the elaboration of it while using the enterprise's funds, while the risk connected with uncertain innovative activity is shared. Therefore, one of the most important factors that create the chances for increasing 
the innovation level as well as the competitiveness of Polish enterprises is the cooperation for innovation.

The realization of internal $R \& D$ activity requires appropriate resources in the form of insufficient financial resources, which is frequently unattainable for most enterprises (especially the smaller ones) and it makes cooperation for innovation an important element of the activity of enterprises. The obtainment of knowledge from the outside is gaining importance, while the research indicates the essential links between the involvement of enterprises in cooperation and the access to new knowledge and technologies [Gallego et al., 2013, p. 2034].

There are numerous reasons why companies cooperate with external organizations. One of them is the mutual activity for innovation. The cooperation of enterprises takes place by means of its various aspects, within which information and knowledge are either free or they may be acquired [Hewitt-Dundas, 2013, p. 95].

Regional cooperation between enterprises as well as between companies and universities and scientific units may be perceived as the basis of the region's competitiveness [Ferreira et al., 2014, p. XIV]. The cooperation between the industry and science has positive influence on the innovation development of enterprises, while the cooperation may adopt various forms [Veugelers, Cassiman, 2005, p. 2]. The cooperation within strategic alliances (two-sided contracts between companies) is becoming more and more important in the innovative activity of enterprises [Teece, 1992, p. 1]. The undertaking of cooperation enables the access to the results of $\mathrm{R} \& \mathrm{D}$ activity and participation in complex innovation processes. The cooperation with other companies or scientific units enables the access to new technological knowledge and the increase of the technological potential of the cooperating entities, which may contribute to faster development of innovations, the improvement of the access to the market, the benefit of scale and also to the reduction of the costs of the enterprise's activity [De Faria et al., 2010, p. 1083]. Not only large international companies, but also small and medium-sized enterprises, are considerably more interested in initiating and developing relationships with other companies with the aim of achieving market benefits and using the new possibilities that would be impossible to achieve individually. Companies get involved both in a formal and informal way in such mutual activities as the cooperation in marketing, resources or purchases [Bönte, Keilbach, 2005, pp. 2-6].

$\mathrm{R} \& \mathrm{D}$ activity is to an increasing degree conducted on a global scale and the increasing part of it is realized in the cooperation with particular scientists, scientific units and the entire units. Multinational enterprises are playing an increasingly large role, similarly to the cooperation between universities and other scientific units and companies in terms of $\mathrm{R} \& \mathrm{D}$ - yet it takes place in both a formal and unofficial way, on the basis of two-sided and multilateral contracts [Podrecznik Frascati..., 2002, p. 19].

The importance of the cooperation for innovation is noticeable also in the development of innovation models. The development of the theory of innovations indicates the evolution of the innovation process to become more complex models that resemble the reality. Till the end of the $20^{\text {th }}$ century there was dominating the 
traditional closed innovation model in accordance with which companies create, develop and commercialize solely their own ideas. What is essential is that the enterprise's competitors may not use the ideas and knowledge that are formed there.

The presently dominating concept of open innovations emphasized the aspects of the widely understood cooperation of the enterprise with the external partners in order to generate and efficiently implement innovations (introduce them on the market). Open models of innovations are characterized by maximizing the value of various ideas both from the enterprise's inside and from the outside, i.e. from its surrounding [Chesbrough et al., 2006, pp. 3-4]. The model of open innovations and the organizational borders between the enterprises and its surrounding are blurred. Technical knowledge in this process of perception is perceived as economic good that is subject to the exchange between the partners of the cooperation [Chesbrough, Garman, 2009, pp. 30-59]. Within open innovation models enterprises seek ideas, inspirations and technologies in the external scientific and research units. The cooperation functions also vice versa. The enterprises having a technology, in both a material and non-material form, earn on the sale of their solutions to other companies.

\section{The research methodology}

The analysis and evaluation of the innovation level and the present cooperation for innovation in enterprises are complex and incur doubts. The methodology used by both GUS and EUROSTAT does not enable unambiguous identification of the cooperation for innovation taking place in enterprises as well as the real innovation level of companies. Such state of affairs reflects the lack of the possibility to make reliable and comparative analysis of activities in terms of the cooperation for innovation on the basis of the generally available data.

The research Author adopted the variant of the partial study. It means that the research comprises a part of the community. The analyzed sample of enterprises was selected at random (in a probabilistic way) from the population of Polish enterprises without return. In the situation where a certain company selected for the research did not give consent to participate in the research or did not exist on the market in the reality, another selection of a company took place in accordance with the aforementioned method so that the selected sample always comprised 100 companies. The selection of the sample for the research needed to meet the criteria mentioned below as regards the subject of the company's functioning. The research comprised industrial enterprises from section C Industrial Enterprise consistent with the Statistical Classification of the Economic Activity of the European Union (NACE Rev. 2). The research accepted both private and public enterprises. The entire research was conducted using the method of direct interview. In the research there were collected 141 questionnaires on the whole, among which 41 were ruled out as incomplete. The research's final results included 100 complete surveys made with the top management and with the owners. 


\section{The analysis of data and the results}

The research constituted the attempt to define the types of cooperation that occur in companies, including the specification of its character and the source of origin. Among the analyzed group of companies for the last three years $25 \%$ of the companies declared cooperation with scientific units - vertical cooperation), whereas 33\% with companies - horizontal cooperation (chart 1).

CHART 1

The percentage participation of companies (\%) in the vertical and horizontal cooperation in terms of the innovations

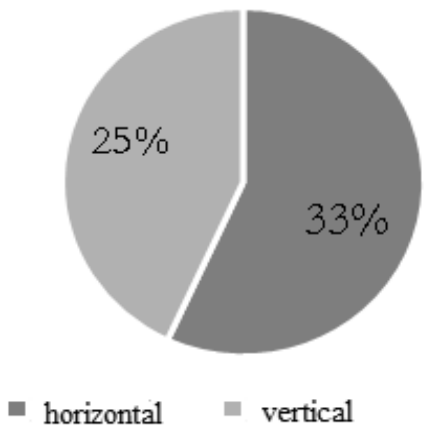

Source: own elaboration on the basis of the research.

CHART 2

The number of partners within horizontal cooperation for innovation undertaken by the companies declaring cooperation with other entities over the last 3 years

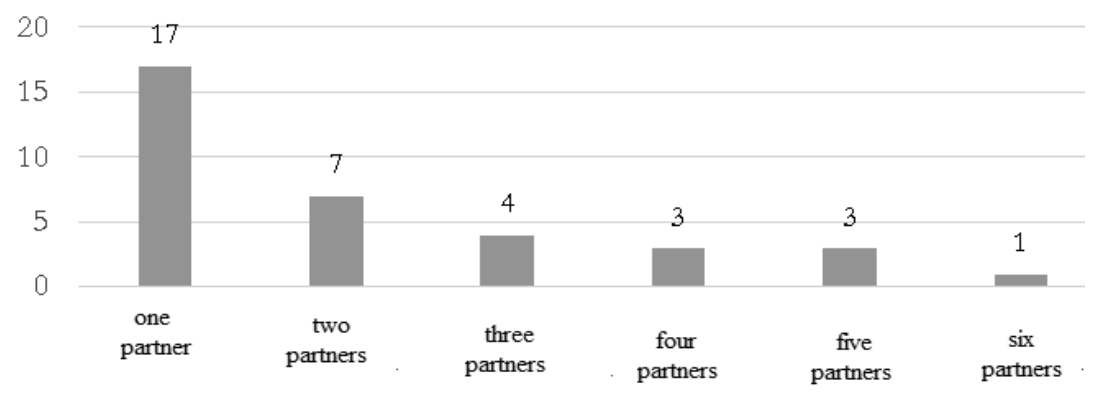

Source: own elaboration on the basis of the research.

The frequency of the undertaken cooperation in the analyzed population was dependent on the number of entities that the discussed enterprises cooperated with. The largest participation was observed among companies that declared cooperation 
with only one entity in a certain time period. In case of the companies that cooperated with two partners - the participation amounted to $7 \%$, with three partners $4 \%$, with four or five partners - 3\% of the analyzed group of enterprises. The cooperation with six entities within the last three years was declared by solely $1 \%$ of the companies (chart 2).

In the horizontal cooperation in terms of innovations the largest participation among the analyzed enterprises was observed in case of the companies that cooperated with consumers $-19 \%$. The second position regarded the cooperation with the companies from the same branch but at the same time not being competitors, with the equipment suppliers $-15 \%$ of the analyzed companies. Approximately $13 \%$ of enterprises cooperated in terms of innovations with subcontractors and cooperating entities, while $7 \%$ - with consulting and advisory companies as well as with direct competition (chart 3).

\section{Partners that companies cooperated with in terms of horizontal cooperation (\%)}

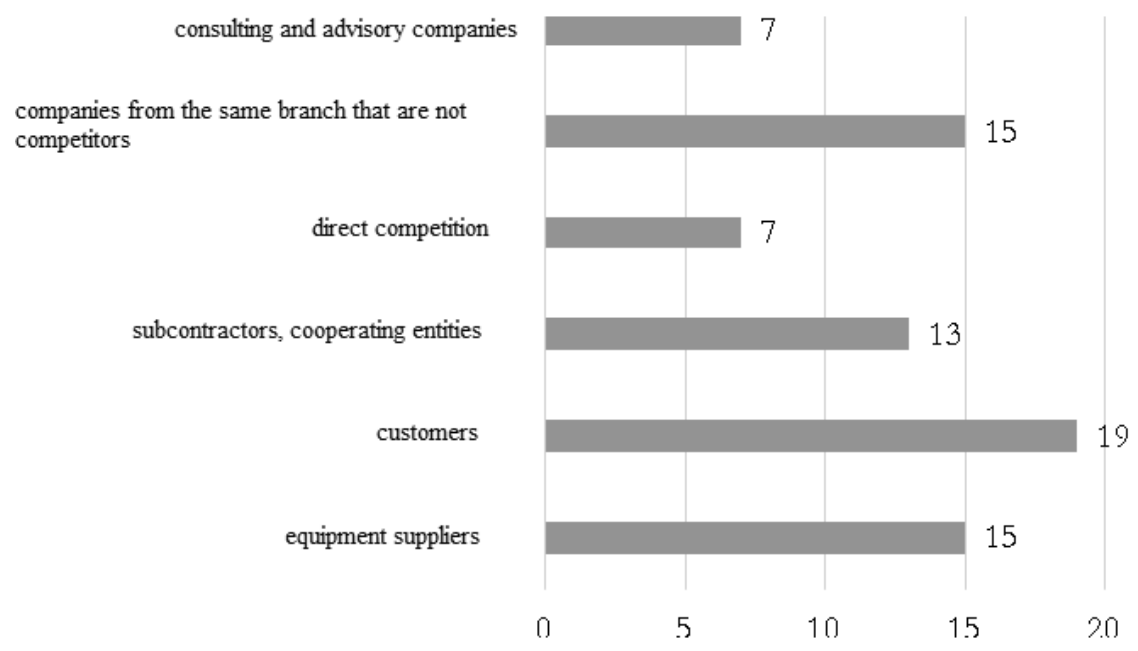

Source: own elaboration on the basis of the research.

Vertical cooperation (scientific units) was based chiefly on the cooperation of the analyzed companies with universities - it was declared by $19 \%$ of the enterprises within the last three years of their activity. The second position (15\%) of the vertical cooperation path in terms of innovations - companies that cooperated with national research and development units. Almost one out of ten of the analyzed companies cooperated with scientists, but solely in the form of informal relationships. Solely $2 \%$ of the enterprises initiated the cooperation for innovations with a private research and development unit (chart 4). 
CHART 4

\section{Partners that enterprises cooperated with in the form of vertical cooperation $(\%)$}

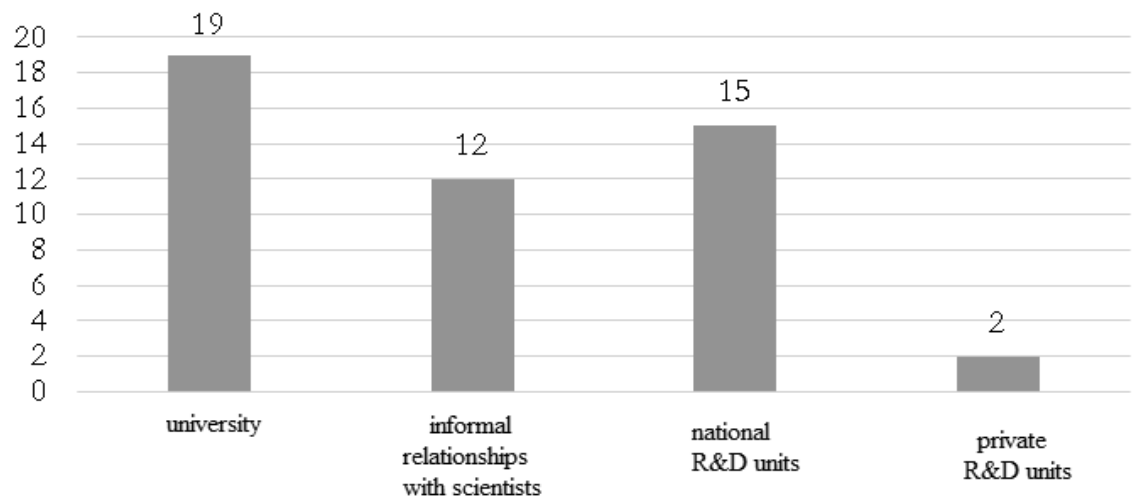

Source: own elaboration on the basis of the research.

The character of cooperation for innovation owing to its scope had mostly national dimension. Most enterprises cooperated with companies and scientific units from Poland. Only 3\% of the enterprises cooperated in the sphere of innovations with a foreign scientific unit, while $4 \%$ of companies firm cooperated with a foreign national research and development institute (chart 5). In case of informal contacts with scientists $2 \%$ of the enterprises declared that they cooperated with scientists from abroad (from Germany and the USA).

CHART 5

National and foreign partners that enterprises cooperated in terms of innovations $(\%)$

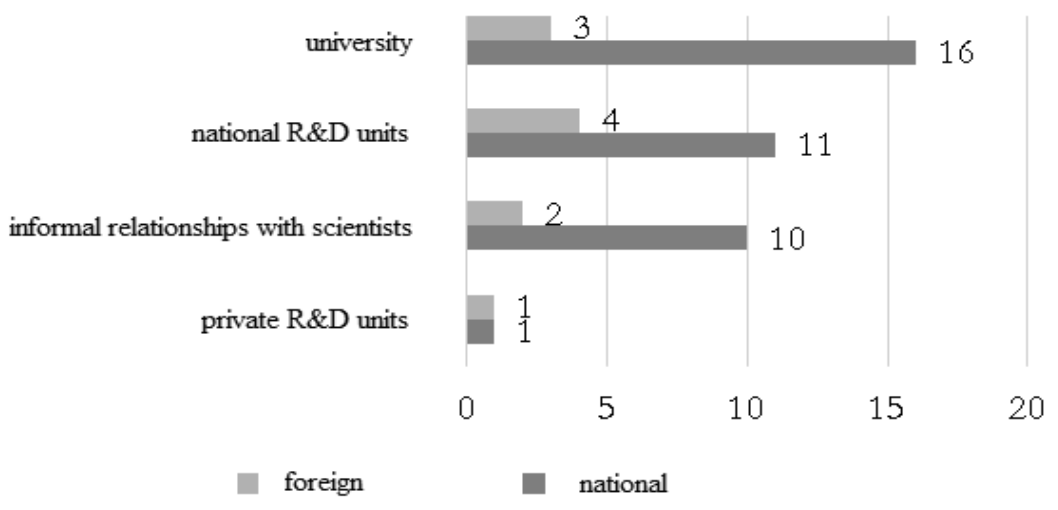

Source: own elaboration. 
In the group of the analyzed enterprises $3 \%$ companies were involved in a jointventure contract, as the result of which they cooperated in terms of innovations. All of these companies were of medium size.

\section{Conclusions}

The paper presents the cooperation for innovation that can be observed in Polish enterprises. Its forms and types as well as their importance in the innovative activity of the enterprises are discussed here.

The research results indicate the insufficient level of enterprises' involvement in the cooperation for innovation, which directly results in their low innovation level and at the same time in the difficulties with achieving competitive advantage. In general, the cooperation with scientific units was declared by one out of four enterprises, whereas the cooperation for innovation with other enterprises - by one out of three enterprises. The frequency of the undertaken cooperation for innovation was not astonishing since enterprises most frequently within the period of three years cooperated solely with one entity. Within horizontal cooperation companies most frequently cooperated with consumers, and less often with the companies from the same branch as well as with the suppliers. The character of the cooperation for innovation (owing to its range) had mostly national dimension.

The analysis presented win the paper implies that Polish enterprises are not sufficiently involved in cooperation - both with enterprises and with scientific units. On its basis the Author made the attempt to formulate the recommendations regarding the cooperation and the application of it in order to improve the innovation level of enterprises:

Recommendation 1: Intensification of the activity in terms of starting the cooperation for innovation with scientific units.

Recommendation 2: Increase of the enterprises' involvement in the cooperation with foreign entities and becoming open to the activities that are addressed at initiating such cooperation.

Recommendation 3: Undertaking of the formal cooperation with scientists and scientific units.

Recommendation 4: Increase of the cooperation with national research units in terms of the mutual elaboration of R\&D solutions.

Recommendation 5: Increase of the enterprises' interest in the cooperation with subcontractors and cooperating entities. 


\section{References}

Bönte W., Keilbach M., 2005, Concubinage or marriage? Informal and formal cooperations for innovation, "International Journal of Industrial Organization", vol. 23(3).

Chesbrough H., Garman A.R., 2009, How Open Innovation Can Help You Cope in Lean Times, Harvard Business Review, vol. 87(12).

Chesbrough H., Vanhaverbeke W., West J., 2006, Open Innovation, researching a New Paradigm, Oxford University Press, New York.

Fagerberg J., Mowery D., Nelson R., 2004, The Oxford handbook of innovation, Oxford University Press.

De Faria P., Lima F., Santos R., 2010, Cooperation in innovation activities: The importance of partners, "Research Policy", vol. 39(8).

Ferreira J.J., Raposo M., Rutten R., Varga A., 2014, Cooperation, Clusters, and Knowledge Transfer, Springer Heidelberg, New York Dordrecht London.

Gallego J., Rubalcaba L., Suárez C., 2013, Knowledge for innovation in Europe: The role of external knowledge on firms' cooperation strategies, "Journal of Business Research", vol. 66(10).

Hewitt-Dundas N., 2013, The role of proximity in university-business cooperation for innovation, "The Journal of Technology Transfer", vol. 38(2).

Innovation Union Scoreboard 2014, 2014, European Union, Belgium.

Innovation Union Scoreboard 2015, 2015, European Union, Belgium.

Innovation Union Scoreboard 2017, 2017, European Union, Belgium.

Podrecznike Frascati. Proponowane procedury standardowe dla badan statystycznych w zakresie driatalności badawcro-rozwojowej, 2002, OECD, Paris.

Rothwell R., 1994, Towards the fifth-generation innovation process, "International Marketing Review", vol. 11.

Teece D.J., 1992, Competition, cooperation, and innovation: Organizational arrangements for regimes of rapid technological progress, "Journal of Economic Behavior \& Organization", vol. 18.

Veugelers R., Cassiman B., 2005, R\&D cooperation between firms and universities. Some empirical evidence from Belgian manufacturing, "International Journal of Industrial Organization", vol. 23. 